\title{
Globe
}

Revue internationale d'études québécoises

\section{Robert Verreault : L'Autre Côté du monde. Le passage à l'âge adulte chez Michel Tremblay, Réjean Ducharme, Anne Hébert et Marie-Claire Biais, Montréal, Liber, 1998, 167 p.}

\section{Jaap Lintvelt}

Volume 3, numéro 2, 2000

URI : https://id.erudit.org/iderudit/1000589ar

DOI : https://doi.org/10.7202/1000589ar

Aller au sommaire du numéro

Éditeur(s)

Globe, Revue internationale d'études québécoises

ISSN

1481-5869 (imprimé)

1923-8231 (numérique)

Découvrir la revue

Citer ce compte rendu

Lintvelt, J. (2000). Compte rendu de [Robert Verreault : L'Autre Côté du monde. Le passage à l'âge adulte chez Michel Tremblay, Réjean Ducharme, Anne Hébert et Marie-Claire Biais, Montréal, Liber, 1998, 167 p.] Globe, 3(2), 190-192.

https://doi.org/10.7202/1000589ar d'utilisation que vous pouvez consulter en ligne.

https://apropos.erudit.org/fr/usagers/politique-dutilisation/ 
femmes, n'attiédit en rien, faut-il le préciser, la chaleureuse admiration que leur porte Monique Bosco. Elle y ajoute en revanche, au-delà de la distance qu'instaurent le genre et l'époque, une empathie profonde pour toutes ces souffrances confuses avec lesquelles se font les livres, et une grande curiosité pour le processus mystérieux par lequel l'écriture et la lecture permettent de survivre. En ce sens, Confiteor et Bis proposent une véritable pédagogie de la littérature, tandis que, sans trahir le pacte abiographique, selon le terme de Claude Leroy, Monique Bosco confesse l'essentiel.

\section{Élisabeth Nardout-Lafarge Université de Montréal}

\section{Robert Verreault}

L'Autre Côté du monde

Le passage à l'âge adulte chez Michel Tremblay, Réjean Ducharme, Anne Hébert et Marie-Claire Blais Montréal, Liber, 1998, 167 p.

La sécularisation de la société au cours de l'histoire occidentale n'empêche pas que le religieux et le sacré resurgissent dans la littérature, laquelle prolonge la " narration mythologique» (p. 9), révélant "l'autre côté du monde ", l'univers mythique. S'inspirant de la mythocritique, Robert Verreault présente une analyse intéressante des rites de passage à l'âge adulte chez quatre auteurs québécois. Dans le premier chapitre, consacré à l'œuvre de Michel Tremblay, il commence par analyser la pièce de théâtre La Maison suspendue (1990), qui révèle les origines mythiques du clan familial évoqué antérieurement dans Les Chroniques du plateau Mont-Royal. À travers la relation incestueuse de Victoire et de Josaphat, Tremblay décrit le mythe paradisiaque de l'unité duelle d'un couple primordial, dont la séparation abolit la plénitude de l'état originel. Verreault montre ensuite comment trois personnages du cycle romanesque du plateau Mont-Royal - Édouard, Marcel et Jean-Marc - ont gardé la nostalgie de l'union des sexes dans l'androgynie. En parcourant plusieurs étapes du rite de passage, Édouard se transforme en duchesse de 


\section{RECENSIONS}

Langeais par le travestissement. Comme il n'arrive pas à se séparer du milieu maternel, le passage à l'âge adulte se solde par un échec, comme c'est le cas, également, pour Marcel. Seul l'androgyne Jean-Marc, grâce au pouvoir créateur de l'écriture, peut réaliser la synthèse des deux mondes, profane et sacré.

La littérature, notamment la poésie de Nelligan et de Rimbaud, exerce aussi une influence identitaire considérable sur Mille Milles de $\mathrm{Le} \mathrm{Nez}$ qui voque (1967) de Réjean Ducharme. L'inceste avec Chateaugué ramène au thème de la nostalgie de l'unité originelle de l'androgynie. Désirant garder la pureté de l'enfance, tous deux refusent le monde adulte. Mais, sous le signe de l'équivoque, suggéré par le titre du roman, Mille Milles est déchiré par des forces contraires. Renonçant à son idéal de pureté, il s'insère enfin dans ce monde adulte que Chateaugué refuse en se suicidant. Cynique, "Mille Milles se révèle semblable à ces adultes qui lui faisaient horreur " (p. 109). Pour compenser sa propre enfance malheureuse, la mère dans L'Enfant chargé de songes (1992) d'Anne Hébert essaie de maintenir ses enfants, Julien et Hélène, dans une interminable enfance édénique. Lydie, dans son rôle diabolique, essaie par contre de séparer les enfants de l'univers maternel, en les initiant à la poésie et à la musique, et en leur faisant subir des épreuves initiatiques. L'initiation échoue cependant, car Hélène se noie dans les rapides après être tombée d'un canot et Julien restera un enfant chargé de songes. Les Enfants du sabbat (1975) sont également analysés comme l'histoire d'une initiation ratée. L'analyse d'Une saison dans la vie d'Emmanuel (1965) décrit enfin un milieu social où les rites religieux semblent avoir perdu leur sens et où beaucoup d'enfants meurent avant d'accéder à l'âge adulte.

Dans sa conclusion, Robert Verreault se réfère à la sociocritique pour signaler des analogies entre les rites de passage à l'âge adulte et l'émancipation identitaire de la société québécoise de la Révolution tranquille. Comme les thèmes relevés sont évoqués également par des romanciers plus récents, Verreault se demande si la " nostalgie du sacré " ne traduit pas " l'influence persistante de la mentalité religieuse sur l'imaginaire québécois" (p. 154). En outre, "la figure de l'écrivain ", ainsi que le rôle de l'écriture, de la poésie et de la 
musique, dans les romans analysés, sont interprétés sur le plan collectif comme "une réponse à la soif du sacré ". "L'écriture salvatrice " est ainsi comparée au "sacre de l'écrivain " de Paul Bénichou.

$$
\begin{array}{r}
\text { Jaap Lintvelt } \\
\text { Université de Groningue (Pays-Bas) }
\end{array}
$$

\section{Lori Saint-Martin}

Le Nom de la mère. Mères, filles et écriture dans la littérature québécoise au féminin

Québec, Éditions Nota Bene, « Essais critiques ", 1999, 331 p.

Le titre de la toute dernière étude de Lori Saint-Martin évoque d'emblée, tout en le déplaçant du père vers la mère, l'un des concepts vedette de la théorie lacanienne, ce fameux nom du père qui place le langage et le symbolique du côté du masculin. C'est dire si SaintMartin ne cherche pas à éviter la polémique, bien au contraire. En effet, dès la quatrième de couverture et tout au long du premier chapitre, essentiellement théorique, l'étude prend fortement position pour l'écriture féminine et entend explorer la relation mère-fille dans l'œuvre d'écrivaines québécoises. Ainsi, à partir des acquis de la psychanalyse et des recherches féministes les plus classiques comme les plus récentes, en sociologie, en histoire culturelle, en anthropologie et autres domaines, l'auteure entreprend de fouiller un vaste corpus sur le thème de la maternité et de la création. Les œuvres étudiées vont, pour le roman, de Gabrielle Roy à Élise Turcotte, en passant par des œuvres aussi variées que celles de Louky Bersianik, Anne Hébert et Nicole Houde qui réécrit le roman de la terre au féminin. L'étude se penche aussi sur la poésie et le théâtre, allant du côté de textes moins canoniques, dont ceux du collectif réuni autour de Pol Pelletier et Louise Laprade. L'une des grandes qualités de l'essai de Lori Saint-Martin est en effet le large échantillon de textes choisis : 52 textes couvrant la majeure partie du XXe siècle. 